\title{
Factors Affecting Consumer Goods Buyers' Choice in E-Commerce Sites: Evidence from Vietnam
}

\author{
Hung Cuong PHAM ${ }^{1}$
}

Received: December 15, 2019 Revised: September 28, 2020 Accepted: October 15, 2020

\begin{abstract}
The main purpose of this study is to find the factors affecting the consumer goods buyers' choice on e-commerce sites in Vietnam. By using the quantitative method, the paper examines the theoretical research model and tests four hypotheses. The sample was drawn from the population of e-commerce sites in Vietnam comprising about 1,000 respondents. This study used the questionnaire method to collect primary data to test the hypotheses. Data analysis of the questionnaire was done using SPSS. The results show that there is a correlation between personal preferences of consumers on colors and brands and their actual final choice on e-commerce sites in Vietnam. The most important factor affecting the consumer goods buyers' choice on e-commerce in Vietnam is the brand of E-commerce site, following by the color and position. Among all educational groups, respondents with a Master degree pay the biggest attention to the site's color attribute, and those with a Bachelor degree pay more attention to the brand attribute. Women pay much more attention to the location of the products on the screen than men, as do consumers with a $\mathrm{PhD}$ degree, over respondents with a Bachelor or Master degree, and foreigners over Vietnamese consumers.
\end{abstract}

Keywords: Color, Brand, Position, E-commerce, Buyer's Choice

JEL Classification Code: M10, M31

\section{Introduction}

With a population of 95 million and $70 \%$ of people aged between 15 to 64 , the developing country that is Vietnam is now the target of many big retail companies from all around the world (Le, 2016). The turnover of Vietnam retail market has reached over $\$ 80$ billion in the past years and was forecast to reach $\$ 100$ billion in 2016 according to a survey by German market research company Statista (Mai, 2016). With mainly young consumers, the country has great potential to facilitate retail development because young people have more buying power. Together with the economic development, income of the middle class has gradually increased. The middle class

${ }^{1}$ First Author and Corresponding Author. Manager, Scientific Management and International Cooperation Department, Foreign Trade University, Ho Chi Minh City Campus, Vietnam [Postal Address: 15D5, Ward 25, Binh Thanh District, Ho Chi Minh City, 700000, Vietnam] Email: phamhungcuong.cs2@ftu.edu.vn

(c) Copyright: The Author(s)

This is an Open Access article distributed under the terms of the Creative Commons Attribution Non-Commercial License (https://creativecommons.org/licenses/by-nc/4.0/) which permits unrestricted non-commercial use, distribution, and reproduction in any medium, provided the original work is properly cited. is increasingly more aware of expenditures, as well as of the luxury retail environment, which is modern and comfortable. In less than 10 years, Vietnam's retail market has welcomed many big international retailers like Circle K, Shop \& Go, Family Mart, Big C, Fivimart, Citimart, Simply Mart, Aeon, Lotte, Parkson, Takashimaya and now, Walmart is also waiting to enter. From the perspective of the consumers, the variety in the market gives more options and modern shopping habits, but from the perspective of competition, the entry of the foreign big retailers can weaken domestic retailers.

E-commerce is big business and getting bigger every day. Growth estimates from eMarketer report that businessto-consumer (B2C) e-commerce sales worldwide will have reached $\$ 1.5$ trillion in 2014 , increasing nearly $20 \%$ over 2013. But not all e-commerce categories are created equal. The most popular e-commerce categories, not surprisingly, are no consumable, but durables and entertainmentrelated products. Nielsen reports that almost half of global respondents in an online survey intend to purchase clothing or make airline or hotel reservations using an online device in the next six months. Other categories growing in prominence for online shopping include e-books, event tickets, sporting 
goods and toys, to name a few. Spending intentions for each category have risen at a double-digit or near doubledigit percentage-point rates since 2011. The online market for buying groceries and other consumable products is comparatively smaller, but is starting to show promise. While durables are the starting point of adoption, consumables are attractive due to the frequency of purchase. Aside from online purchasing, digital is an increasingly important research and engagement platform. Consumable categories are not likely to reach the same level of online prominence as non-consumable categories due to the hands-on buying nature and perishability of the products, but the market is wide open and an eager audience is at the ready. This study provides clarity about global consumers' buying intentions for both consumable and no consumable categories in the growing e-commerce landscape, which answers important questions for brand marketers and retailers on who is buying what and how they can achieve greater success. Consumer goods markets include all individuals who buy goods or services to consume for themselves and their families. The consumer market is the last market where economic activities are organized to serve it. When analyzing consumer goods market, it is necessary to identify consumers, objects and objectives of buyers, operational organizations, purchases and stores and retail points.

The blooming for retailing business happened in 2015 after the liberalization of the retail sector when Vietnam joined WTO. In 2016, retail sales grew by $10.2 \%$, faster than a 9.8\% growth in 2015 (General Statistics Office of Vietnam, 2016). Even though modern retail formats such as discount store and vending machines have appeared in Vietnam long time ago, they are still primitive. On the other hand, e-commerce and online sales market in Vietnam have great potential, but not really booming yet. With a large population of over 95 million as well as fast development of Internet users, the retail market of Vietnam still has plenty of room for domestic and foreign retailers. Therefore, the study on factors affecting consumer goods buyers' choice in e-commerce sites in Vietnam is necessary.

\section{Literature Review}

According to Kotler et al. (2013), consumer behavior is defined as a total of actions that occur during the process of identifying needs until purchasing and after purchasing products. In other words, consumer behavior is how individuals make decisions that will use their available resources such as time, money, effort, etc. Consumer behavior is the interaction between the stimulating factors of the environment and people's perceptions and behaviors, but through that interaction, people change their lives. According to this definition, the concept of consumer behavior is viewed from the perspective of interaction, mutual interaction between people and the external environment. Consumer behavior is also defined as a deep commitment to repeat purchase, warranty of a preferred product or future service. Therefore, the understanding of the determinants of retaining customers can facilitate managers to focus on key factors that lead to consumer behavior. Quality, cognitive values and satisfaction have all been proven to be good predictors of behavioral intent. In general, all definitions of consumer behavior focus on the aspects of identification, information revenue, purchasing reviews, consumer purchasing reactions and relationships. Behavioral trends can be identified and evaluated by "Attitude" and "Behavior". "Attitude" refers to a specific desire to continue the relationship with a service provider, where the "Behavior" view refers to the concept of repeat guarantee. Customers can develop an "Attitude" based on previously collected information without practical experience. This information can create an attitude of bias or opposition to suppliers from their images in the market.

E-commerce is defined as the buying and selling of goods and services over the Internet, while E-business - the conduct of business on the Internet including, not only buying and selling, but also serving customers and collaborating with business partners (Baltzan et al., 2010). According to Chaffey (2007), E-commerce is the form of trading goods and service through the computer network worldwide also known as the electronic market, virtual market, e-commerce or e-business. It is the virtual trading process through the transmission of data between computers in the distribution policy of marketing. The direct commercial or relationship between the supplier and the customer is conducted over the Internet. E-commerce is aimed at enhancing the competitiveness of an organization by deploying innovative information and communications technology throughout an organization and beyond, through links to partners and customers. It does not simply involve using technology to automate the existing process, but should also involve using technology to help change these processes (Chaffey, 2007). E-commerce processes can be viewed from the inside of an enterprise (supply chain management, e-procurement) or from outside the enterprise (electronic market, e-commerce). For a country, e-commerce is seen as the driving force behind the development of the information technology industry, a key industry that is seen as a major contributor to the foundations of the new world economy. This is an opportunity for global economic integration (Chaffey, 2007). The e-commerce market has been booming in Vietnam since 2015. The number of online transactions and e-commerce sites has increased steadily in recent years. However, the number of online sales in Vietnam is still not high, and consumers are still limited in buying from websites when they have to provide too much information during and after the shopping process (Nguyen \& Khoa, 2019). 
Consumer behavior is understood as the reactions that individuals express in the process of making decisions to buy goods and services. Knowing customer behavior will help businesses offer products, select marketing channels, and message about other factors of marketing mix. Consumer behavior is influenced by key factors such as culture, society, personal, psychological and marketing factors. All these factors give us bases to know how to approach and serve customers more effectively. Therefore, studying consumer behavior along with factors affecting consumer behavior helps marketers identify and predict consumption trends of specific customers. From there, make timely and effective marketing plans. The behavior of buyers is greatly influenced by factors of the process affecting buyers' perceptions including marketing factors (products, prices, distribution channels and marketing) and other factors related to buyers' characteristics (cultural, social, personal and psychological). Since then, impact on the decision-making process of buyers to purchase behavior and purchase decisions (Kotler et al., 2013).

Mazurova (2017) stated that the most influential factor to the online consumer decision-making process is brand, the second most important attribute is the color, which was estimated half as important as brand, and the least important attribute is the position on the screen. Additionally, this research identified the main differences regarding consumers stated and revealed preferences regarding these three attributes. Also, previous studies identify three factors that are the most influential on the final purchasing decision of consumers in online shopping: brand, color, and position of the product on the screen. Dick (1990) stated that the importance of the brand on consumer perception increases during online shopping due to the limited number of other attributes of the product, which the consumers can examine such as taste, smell, texture or a complete list of ingredients. As a result, the consumer primarily relies on the brand image and reputation. However, Lüscher (1969) stated that using certain colors makes it possible to control the perception of products by the customers as each color causes a particular predictable reaction of a person and influences his/her emotions in a certain way.

Additionally, Enquiro (2005) identified that consumers track the product on the screen according to Golden Triangle pattern and position attribute, which was being seen as important and influential on consumer behavior. However, studying the theoretical background of online consumer behavior, they have not found any comparison analysis of the influence of these three factors identifying the most influential of them, even though the individual importance of each particular attribute on consumer's decision-making process has been analyzed frequently. Four factors influence positively customer satisfaction regarding the quality of online services in Tiki.vn e-commerce platform in the order of descending strength: trust, customer service, web design, and safety (Giao, 2020). The factor of customer satisfaction is a determinant of consumer loyalty and repurchases intention (Ilyas et al., 2020). Apart from convenience and trust, four factors - efficiency, reliability, citizens support, and transparency - are important measures of system quality, information quality, service quality and relative benefits of e-government, which in turn positively and significantly impact citizens' satisfaction with the online public services (Nguyen et al., 2020). Product risk, financial risk, security risk, and privacy risk impacted on perceived satisfaction. Besides, product risk, privacy risk, and perceived satisfaction influenced purchase intentions. Thus, this study focused on the influences of product risk, financial risk, security risk, and privacy risk on their cognitive attitudes toward websites. That means the more consumers are concerned with security, the more they avoid shopping online (Tran, 2020).

The knowledge about consumer's decision-making process and preferences in online purchasing is crucial for building a new marketing strategy or making changes to the existing strategy so that it is oriented to a particular market audience, satisfies consumer's needs and works on increasing sales. When studying the driving forces of consumer buying behavior, it is not possible to eliminate various cultural, social, psychological and individual factors from the process as they make a crucial influence on the final choice of a consumer and his/her individual preferences of the products itself and its various attributes, such as brand, color and other features (Park \& Kim, 2003).

By using certain colors, it is possible to control the perception of the advertisements and products by the customers. The perception of a color changes depending on the associations related to the color. According to previous studies, there is a general description of the emotions and associations that different colors evoke (Dick, 1990; Lüscher, 1969). Lauren (2011) stated that the influence of colors on customer perception depends on different factors including associative learning, individual preferences, cultural factors, gender and age preferences, and associations with a particular brand or goods. The perception of color is considered from the perspective of associative learning, claiming that people tend to have the emotional response on the particular color based on the associations with objects or situations (Bellizzi et al., 1983; Elliot \& Niesta, 2007; Schlack \& Albright, 2007).

According to Hulbert and Ling (2007), there were significant differences between the color preferences by women and men. Some of them differ only by the percentage of preferences, such as, for example, $76 \%$ against $56 \%$ of preference for the blue color by women and men, respectively. Other differences are opposite among genders such as, for example, women prefer purple, pink and yellow colors, while men mostly prefer black, orange (instead of yellow), brown and green colors. When scrolling the 
web-pages and searching for the products, the customer stops only for several seconds on each page and this time must be enough for the product to make the greatest impression on the customer such that the customer is ready to order it (Enquiro, 2005). According to the study conducted by the University of Tulsa, position takes the third place among the factors that influence customer choice. The other two factors are relevance of the product and its description. Position follows them according to the level of its significance.

According to Google Eye-tracking research (2005), the Golden Triangle area catches the most intense eye scan activity. Consumers restrict scan activity to the Golden Triangle area of the page. If the target good is not placed in the area of the Golden Triangle area, the chances that the customer will stop his/her final choice on the product are very low. Consumer's eyes tend to orient themselves in the upper left corner of the page and then move down the left side of the page. The scan activity quickly degrades when moving from up to down positions of the objects on the screen. So, first a customer looks to the upper left corner, and it is the initial starting point of the eyes (rectangles 1 and 2), then moving down, scanning the information from left to right (rectangles 4). This result has a big importance for marketers if they want to attract customer's attention to unpopular products, placing them among popular products in the key locations (Enquiro, 2005). Knowledge about the area of the highest consumer's visual attention in the combination with a valuable product is essential for marketing strategy.

According to previous research, brand is much more than just a name or a symbol of the company. Brand addresses itself to the feelings, emotions and subconscious mind of a consumer. Brand evokes the associations, saved in the consumer's memory and aims to differentiate a retailer from its competitors, creating intangible benefits for the customer (Rigaux-Bricmont, 1981; Dick, 1990). According to Dick (1990), the importance of the brand name of the product increases when there is limited information about other attributes and characteristics of the product. Thus, when buying online, customers do not have the possibility to examine many features, characteristics and attributes of a product, which are important for them. So, a customer relies on the brand name, which $\mathrm{s} /$ he has already known, in order to decrease the risks and uncertainties associated with an online purchase (Dawar et al., 1994). In the consumer's mind, brand name is strongly associated with and guarantees the quality and features of a product, which customer cannot check. Well-known brand works as a natural visual anchor or magnet for the consumer's eyes in the process of online shopping. In contrast to unknown brands, well-known brand for a consumer provides much more information about even an unknown product, which is spread out via media, advertisement, promotion campaigns, world-of-mouth communication and previous use of the brand.

\section{Research Methods and Materials}

By using the quantitative method, the paper examines the theoretical research model and tests the four hypotheses. The sample was drawn from the population of e-commerce sites in Vietnam totaling 1,000 respondents. This research used the questionnaire method to collect primary data to test the hypotheses and answer the three research objectives. The constructs and the pool of questionnaire items were generated in two steps: an extensive literature review, and then focus group discussions.

\section{Results and Discussion}

The data, obtained during the experiment was analyzed with the SPSS software. The importance and utility indexes were calculated for the whole sample as well as for each of the sub-groups: Gender, Education and Nationality (Table 1).

The importance index indicates the level of importance of each particular attribute for a group of participants as potential customers, which allows answering the main research question: which attribute of a product, brand, color or the position on the screen, mainly influences the consumer's final choice. Utility index indicates the likelihood that a particular brand, color or the position on the screen will be chosen by a customer when performing online shopping - the higher the index (positive), the more likely that a particular attribute will be chosen by a customer. The negative index indicates that a particular attribute-level discourages people from choosing it.

The index of importance indicates that, among the whole sample of the participants, the brand attribute is the most important and influential for the customer's choice of the product. The second most important attribute is color, having the index of importance almost twice lower than the brand (63.2/31.7). The least influential attribute for consumer choice is the position of the product on the screen, having the index of importance for the respondents equal to 5.1.

Considering the educational level of participants, the highest importance brand factor has for consumers with a Bachelor degree and the smallest importance for those with a $\mathrm{PhD}$ degree. Within this group, color attribute has the highest importance for respondents with a Master degree than for respondents with a Bachelor or $\mathrm{PhD}$ degree. And position attribute records a very high index for respondents with a PhD degree compared to the Bachelor or Master sub-groups. With respect to nationality, we can see that brand is more important for Vietnamese respondents than for non-Vietnamese. The indexes of importance of the color attribute are not very distinctive for both sub-groups. However, for non-Vietnamese participants the position attribute is almost three times higher than for Vietnamese (Table 2). 
Table 1: Sample survey information

\begin{tabular}{|c|c|c|c|c|}
\hline \multicolumn{2}{|r|}{ Sample } & Frequency & $\%$ & Accumulated \% \\
\hline \multicolumn{5}{|l|}{ Gender } \\
\hline & Male & 533 & 52.00 & 57,8 \\
\hline & Female & 492 & 48.00 & 100 \\
\hline \multicolumn{5}{|l|}{ Age } \\
\hline & 18 to 30 years old & 290 & 28.29 & 39,1 \\
\hline & 31 to 40 years old & 364 & 35.51 & 67,0 \\
\hline & 41 to 50 years old & 242 & 23.61 & 87,4 \\
\hline & Over 50 years old & 129 & 12.59 & 100,0 \\
\hline \multicolumn{5}{|c|}{ Education } \\
\hline & Under Bachelor & 246 & 24.00 & 20,0 \\
\hline & Bachelor & 351 & 34.24 & 44,3 \\
\hline & Master & 306 & 29.85 & 90,4 \\
\hline & Doctor & 222 & 21.66 & 100,0 \\
\hline \multicolumn{5}{|l|}{ Income } \\
\hline & Under 10 million VND & 783 & 76.39 & 36,1 \\
\hline & 10 to 20 million VND & 207 & 20.20 & 82,6 \\
\hline & 21 to 30 million VND & 30 & 2.93 & 97,8 \\
\hline & Over 31 million VND & 5 & 0.49 & 100,0 \\
\hline
\end{tabular}

Table 2: Importance values obtained

\begin{tabular}{|l|c|c|c|c|c|c|c|c|}
\hline \multirow{2}{*}{} & & \multicolumn{2}{|c|}{ Gender } & \multicolumn{3}{c|}{ Education } & \multicolumn{2}{c|}{ Nationality } \\
\cline { 3 - 8 } & & Female & Male & Bachelor & Master & Doctor & Vietnamese & Non- Vietnamese \\
\hline Brand & 63.2 & 59.34 & 61.65 & 69.04 & 52.73 & 50.16 & 63.38 & 52.21 \\
\hline Color & 31.7 & 27.17 & 35.99 & 26.30 & 42.30 & 29.60 & 31.94 & 35.48 \\
\hline Position & 5.1 & 13.48 & 2.34 & 4.65 & 4.96 & 20.23 & 4.67 & 12.3 \\
\hline
\end{tabular}

Table 3: Summary of utilities for brand, color, and position on screen

\begin{tabular}{|c|c|c|c|}
\hline & Most preferable & Less preferable & Least preferable \\
\hline Brand & $\begin{array}{c}\text { Tiki.vn (0.56); } \\
\text { Lazada.vn (0.67) }\end{array}$ & $\begin{array}{l}\text { chotot.com } \\
\text { thegioididong.vn }\end{array}$ & $\begin{array}{c}\text { Muaban.net (0.012) } \\
\text { Enbac.com }\end{array}$ \\
\hline Color & Blue (0.49) & $\begin{array}{l}\text { Brown } \\
\text { Yellow }\end{array}$ & $\begin{array}{c}\text { Green }(-0.367) \\
\text { Purple }(-0.017) \\
\text { Red }(-0.045)\end{array}$ \\
\hline Position & Upper-left (0.09) & Upper-right & $\begin{array}{l}\text { Bot-left }(-0.065) \\
\text { Bot-right }(-0.073)\end{array}$ \\
\hline
\end{tabular}

Considering the indexes of utilities, it can be observed that the most popular sites that is mostly likely to be chosen by the respondents is Tiki.vn, Lazada.vn, thegioididong.vn, chotot.com, Muaban.net, and Enbac.com; the most popular color among participants is blue and the most preferable position of the product on the screen is upper left corner (Table 3).

The least preferable brand within the whole sample are Muaban.net and Enbac.com; the least preferable colors are green, purple and red; the least preferable positions of the product on the screen are bottom left and bottom right. 
Table 4: Exploratory factor analysis

\begin{tabular}{|l|c|}
\hline \multicolumn{3}{|l|}{ Kaiser-Meyer-Olkin) Measure of Sampling Adequacy } \\
and Bartlett's Test
\end{tabular}

Bartlett's test results show a correlation between the variables in the overall population $(\mathrm{sig}=0.00<0.05$ ). At the same time KMO coefficient $=0.799>0.5$ indicates that factor analysis to group variables together is appropriate and is suitable data for factor analysis because the Bartlett's test indicated the strong relationship among variables. It also checks whether the correlation matrix is an identity matrix by testing the null hypothesis. Kaiser-Meyer-Olkin (KMO) Test is a measure of how suited the data is for factor analysis. The test measures sampling adequacy for each variable in the model and for the complete model. The statistic is a measure of the proportion of variance among variables that might be common variance. The lower the proportion, the more suited the data is to factor analysis. KMO returns values between 0 and 1 . In this research, KMO is 0.799 indicating that the sampling is adequate (Table 4 ).

\section{Conclusions}

The study answers the research question concerning the correlation between personal preferences of consumers for colors and brands and actual final choice in e-commerce sites of consumer goods buyers in Vietnam. The study can surely say that consumers cannot identify their preferences accurately and the answers regarding their preferences are completely different from their actual choices of the products, as well as their personal rating of the importance of the factors influence their choices when shopping on E-commerce sites in Vietnam. The factors that consumers consider as the most important, does not usually match the actual rating, made by the consumers in the real purchasing decision-making process.

Among all educational groups, respondents with a Master degree pay the biggest attention to the color attribute, and respondents with a Bachelor degree pay more attention to the brand attribute. Women pay much more attention to the location of the products on the screen than men, as do consumers with a $\mathrm{PhD}$ degree over other respondents with the Bachelor or Master degree, and foreigners over Vietnamese consumers. For foreigners, brand attribute is slightly less important than for Vietnamese consumers. Furthermore, in the process of the research, this paper has identified that the most preferable brands of e-commerce sites are Tiki.vn (0.56) and Lazada.vn (0.67), and the least preferable is a factual absence of brand or unknown brand for both Vietnamese and non-Vietnamese respondents. Besides, the study also identified consumer preferences for the colors for a particular good, and they are blue, brown and yellow. The least preferable colors for the consumers in our experiment were green, purple and red. Thus, regarding the color preferences, this research can conclude that people follow the preferences in their color choice, based on the associations that these colors evoke in case of a particular product, as well as associations to the particular brand name.

\section{References}

Baltzan, P., Phillips, A., Lynch, K., \& Blakey, P. (2010). Business driven information systems. Sydney, Australia: The McGrawHill Companies.

Bellizzi, J., Crowley, A., \& Hasty, R. (1983). The effects of color in store design. Retail, 59(1), 21-45.

Chaffey, D. (2007). E-business and e-commerce management $\left(1^{\text {st }}\right.$ ed). Harlow, UK: Financial Times Prentice Hall.

Dawar, N., \& Parket, P. (1994). Marketing Universals: Consumers use of brand name, price, physical appearance, and retailer reputation as signals of product quality. Market, 58, 23-57.

Dick, A. (1990). Memory-based inferences during consumer choice. Consumer Research, 17, 82-93.

Elliot, A., \& Niesta, D. (2008). Romantic red: red enhances men's attraction to women. Personality and Social Psychology, 95(5), 10-17.

Enquiro, G. (2005). Google eye-tracking report. Eyetools and DidIt $156-185$.

Giao, H. N. K. (2020). Customer Satisfaction at Tiki.vn E-Commerce Platform. Journal of Asian Finance, Economics and Business, 7(4), 173-183. https://doi.org/10.13106/jafeb.2020.vol7. no4.173

Hulbert, A. C., \& Ling, Y. (2007). Biological components of sex differences in color preference. Current. Biology, 17, 24-37.

Ilyas, G. B., Rahmi, S., Tamsah, H., Munir, A. R., \& Putra, A. H. P. K. (2020). Reflective Model of Brand Awareness on Repurchase Intention and Customer Satisfaction. Journal of Asian Finance, Economics and Business, 7(9), 427-438. https:// doi.org/10.13106/jafeb.2020.vol7.no9.427

Kotler, P., Armstrong, G., Harris, L. and Piercy, N. (2013). Principles of Marketing European ( $6^{\text {th }}$ ed). Edinburgh, UK: Pearson Education Limited.

Lauren, I. L. (2012). Exciting red and competent blue: the importance of color in marketing. Journal of the Academy of Marketing Science, 40(5), 711-727.

Le, T. (2016). Attractions from the retail market in Vietnam [online] JLL. Available at: http://www.joneslanglasalle.com.vn/vietnam/ vi-vn/news/64/suc-hut-tu-mieng-banh-ban-le-tai-viet-nam. 
Lüscher, M. (1969). The Lüscher colour test. New York, NY: Simon \& Schuster.

Mai, T. (2016). The Vietnam retail market: from underground competition to publicity [online] Baomoi.com. Available at: http:/www.baomoi.com/thi-truong-ban-le-viet-nam-tu-canhtranh-ngamden-cong-khai/c/18600659.epi [Accessed 30 Apr. 2017].

Mazurova, E. (2017). Exploratory Analysis of the Factors Affecting Consumer Choice in E-Commerce: Conjoint Analysis. Journal of Information Systems Engineering \& Management, 2(2), 12.

Nguyen, P. (2017). Analysis of retail market in Vietnam, Case: Vingroup. Helsinki Metropolia University of Applied Sciences.

Nguyen, H. M., \& Khoa, B. T. (2019). The Relationship between the Perceived Mental Benefits, Online Trust, and Personal Information Disclosure in Online Shopping. Journal of Asian Finance, Economics and Business, 6(4), 261-270. https://doi. org/10.13106/jafeb.2019.vol6.no4.261
Nguyen, T. T., Phan, D. M., Le, A. H., \& Nguyen, L. T. N (2020). The Determinants of Citizens' Satisfaction of E-Government: An Empirical Study in Vietnam. Journal of Asian Finance, Economics and Business, 7(8), 519-531. https://doi. org/10.13106/jafeb.2020.vol7.no8.519

Park, C., \& Kim, Y. (2003). Identifying key factors affecting consumer purchase behaviour in an online shopping context. International Journal of Distribution and Management, 3, 37-67.

Rigaux-Bricmont, B. (1981). Influence of Brand Name and Packaging on Perceived Quality. Association for Consumer Research, 9, 472-477.

Schlack, A., \& Albright, T. (2007). Remembering visual motion: neural correlates of associative plasticity and motion recall in cortical area. Neuron, 53, 81-89.

Tran, V. D. (2020). The Relationship among Product Risk, Perceived Satisfaction and Purchase Intentions for Online Shopping. Journal of Asian Finance, Economics and Business, 7(6), 221-231. https://doi.org/10.13106/jafeb.2020.vol7.no6.221 